\title{
Association of prematurity, lung disease and body size with lung volume and ventilation inhomogeneity in unsedated neonates: a multicentre study
}

\author{
G Hülskamp ${ }^{1,2}$ S Lum, ${ }^{1} \mathrm{~J}$ Stocks, ${ }^{1}$ A Wade, ${ }^{3}$ A F Hoo, ${ }^{1} \mathrm{~K}$ Costeloe, ${ }^{4} \mathrm{~J}$ Hawdon, ${ }^{5}$ \\ K Deeptha, ${ }^{6}$ J J Pillow ${ }^{6}$
}

\begin{abstract}
- Additional details are published online only at http:// thorax.bmj.com/content/vol64/ issue3

${ }^{1}$ Portex Anaesthesia, Intensive Therapy and Respiratory

Medicine Unit, UCL, Institute of Child Health and Great Ormond Street Hospital for Children NHS Trust, London, UK; ${ }^{2}$ Department of Paediatrics, Westfälische Wilhelms-Universität, Münster, Germany; ${ }^{3}$ Paediatric

Epidemiology and Biostatistics Unit, UCL, Institute of Child Health, London, UK; ${ }^{4}$ Academic Unit of Paediatrics, Barts and the London School of Medicine and Dentistry, Neonatal Unit, Homerton University Hospital, London, UK; ${ }^{5}$ Neonatal Unit, University College London Hospital, London, UK; ${ }^{6}$ School of Women's and Infants' Health, University of Western Australia, Perth, Australia
\end{abstract}

Correspondence to:

Dr G Hülskamp, Department of

Paediatrics, Universitätsklinikum, Westfälische Wilhelms-

Universität and Department of

Paediatrics, Clemenshospital

Münster, Düesbergweg 124

D-48153 Münster, Germany;

g.huelskamp@

clemenshospital.de

Received 13 May 2008 Accepted 23 October 2008

Published Online First

3 December 2008

\begin{abstract}
Background: Previous studies have suggested that preterm birth with or without subsequent chronic lung disease is associated with reduced functional residual capacity (FRC) and increased ventilation inhomogeneity in the neonatal period. We aimed to establish whether such findings are associated with the degree of prematurity, neonatal respiratory illness and disproportionate somatic growth.
\end{abstract}

Methods: Multiple breath washout measurements using an ultrasonic flowmeter were obtained from 219 infants on 306 test occasions during the first few months of life, at three neonatal units in the UK and Australia. Tests were performed during unsedated sleep in clinically stable infants (assigned to four exclusive diagnostic categories: term controls, preterm controls, respiratory distress syndrome and chronic lung disease). The determinants of neonatal lung function were assessed using multivariable, multilevel modelling.

Results: After adjustment for age and body proportions, the factors gestation, intrauterine growth restriction and days of supplemental oxygen were all significantly associated with a reduced FRC. In contrast, increased ventilation inhomogeneity (elevated lung clearance index) was only significantly associated with duration of supplemental oxygen. After adjusting for continuous variables, diagnostic category made no further contribution to the models. Despite using identical techniques, unexpected inter-centre differences occurred, associated with the equipment used; these did not alter the negative association of preterm delivery and disease severity with lung function outcomes.

Conclusion: Reduction in FRC is independently associated with prematurity, intrauterine growth restriction and severity of neonatal lung disease. Determinants of lung function shortly after birth are highly complex in different disease groups.

Abnormal lung development in preterm infants caused by intrauterine and early postnatal factors ${ }^{1}$ is characterised by impaired alveolarisation and dysmorphic vasculogenesis. ${ }^{2}$ These features are the pathological hallmarks of chronic lung disease of infancy (CLD, frequently referred to as bronchopulmonary dysplasia). Despite increasing survival of extremely preterm infants, the incidence of CLD remains high. ${ }^{3}$ While infants are generally categorised as having CLD or not based on the need for mechanical ventilation and/or supplemental oxygen $\left(\mathrm{O}_{2}\right)$ at 36 weeks postmenstrual age (PMA), the reality is that a continuum of disease severity is observed. ${ }^{4-7}$ Accurate and non-invasive bedside techniques that evaluate the functional consequences of these structural changes are urgently required. ${ }^{38}$

Measurements of lung volume are relevant for assessing lung growth and development and for interpreting volume dependent lung function parameters. Functional residual capacity (FRC), the resting lung volume at end expiration, is the only "static" lung volume that can be readily assessed in non-cooperative infants and very young children. As summarised recently, ${ }^{9}$ FRC is initially low in CLD but subsequently normalises or becomes elevated in later infancy, secondary to airway obstruction. The association between these findings and the degree of prematurity, the disproportionate somatic growth pattern that may accompany severe illness or preterm delivery, and the severity of neonatal lung disease has not been investigated thoroughly. Furthermore, the lack of commercially available equipment for assessing lung function in small unsedated infants has limited widespread use of these techniques.

Infant whole body plethysmography ${ }^{10}$ is unsuitable for assessing FRC at the bedside or in unstable or ventilated infants. An alternative method, the multiple breath inert gas washout (MBW) technique, has recently gained popularity because of the potential for simultaneous evaluation of FRC and ventilation inhomogeneity. ${ }^{811} 12$ A prototype, commercially available ultrasonic flowmeter based on that described by Buess and colleagues, ${ }^{13}$ has been used to measure FRC and indices of ventilation inhomogeneity in experimental animal models ${ }^{14}$ and in non-ventilated ${ }^{15}$ and ventilated ${ }^{14}$ infants and children. Accuracy of FRC measured using the ultrasonic flowmeter $\left(\mathrm{FRC}_{\mathrm{US}}\right.$ ) has been confirmed in vitro ${ }^{1516}$ and in vivo. ${ }^{17}$ The use of this device to evaluate the impact of antecedent factors on lung development in preterm infants has not been reported.

The primary aim of this study was to assess the association of gestation, intrauterine growth and respiratory illness with lung volume and ventilation inhomogeneity during the neonatal period. The hypothesis to be tested was that: (1) preterm delivery (per se); (2) the degree of prematurity and intrauterine growth pattern; and (3) the severity of any neonatal respiratory disease are independently associated with lower FRC and reduced efficiency of ventilation during the first months of life after resolution of any acute respiratory illness. 
Table 1 Population characteristics according to diagnostic category

\begin{tabular}{|c|c|c|c|c|}
\hline & FTC & PTC & RDS & CLD \\
\hline Total No (\% male) & $64(44)$ & $59(42)$ & $54(57)$ & $42(57)$ \\
\hline HUH No (\% male) & $25(40)$ & $22(50)$ & 7 (42) & $17(47)$ \\
\hline UCLH No (\% male) & $4(25)$ & $10(50)$ & $5(60)$ & $7(71)$ \\
\hline KEMH No (\% male) & $35(48)$ & $27(33)$ & $42(60)$ & $18(61)$ \\
\hline Gestation (weeks) & $39.7(1.2)$ & $33.5(1.9)$ & $29.6(2.3) \dagger$ & $26.6(2.1) \ddagger \S$ \\
\hline Birth weight $(\mathrm{kg})$ & $3.36(0.41)$ & $1.85(0.50)$ & $1.32(0.45) \dagger$ & $0.89(0.29) \$, \S$ \\
\hline Birth weight $z$ score ${ }^{22}$ & $-0.12(0.90)$ & $-0.78(1.19)$ & $-0.34(1.18)$ & $-0.58(0.29)$ \\
\hline Ethnicity (\% Caucasian) & 73 & 70 & 85 & $64 \S$ \\
\hline In utero smoke exposure (\%) & 13 & 22 & 21 & 12 \\
\hline Antenatal steroids (\%) & - & 62 & $87 \dagger$ & $86 \%$ \\
\hline PROM (\%) & - & 19 & 15 & 26 \\
\hline Surfactant & - & - & 83 & 95 \\
\hline Total respiratory support (days)* & - & $0.0(0.0 ; 0.0)$ & $4.8(1.3 ; 21) \dagger$ & $42(16 ; 70) \div, \S$ \\
\hline Total invasive ventilation (days)* & - & - & $0.6(0.2 ; 1.0)$ & $4.8(0.6 ; 39) \S$ \\
\hline $\mathrm{O}_{2}$ requirement (days)* & - & $0.0(0.0 ; 0.0)$ & $1.5(0.0 ; 16)$ & $88(75 ; 156) \ddagger$ \& \\
\hline
\end{tabular}

Results expressed mean (SD) if not stated otherwise. Invasive ventilation indicates tracheal tube in place.

* Median (interquartile range). † Significant difference between PTC and RDS. †Significant difference between PTC and CLD.

$\S$ Significant difference between RDS and CLD (see online supplement for details). ๆTotal respiratory support (days): total number

of days the child received either invasive (ie, intubated) or non-invasive (continuous positive airway pressure) ventilatory support.

CLD, Chronic Lung Disease; FTC, full term controls; HUH, Homerton University Hospital; KEMH, King Edward Memorial Hospital;

PROM, prolonged rupture of membranes; PTC, preterm controls; RDS, respiratory distress syndrome; UCLH, University College

London Hospital.

\section{METHODS}

\section{Study design}

This study was designed as an evaluation of lung function in unsedated preterm and term infants during the first months of life. Studies were approved by the local research ethics committees and written informed parental consent was obtained prior to lung function testing.

\section{Study subjects}

Infants were recruited from the neonatal units of Homerton University Hospital (HUH) and University College London Hospital (UCLH), in London, UK, and King Edward Memorial Hospital (KEMH), Perth, Australia, using established recruitment protocols. ${ }^{10}{ }^{18}$ Infants were classified according to gestation and clinical status into four exclusive diagnostic categories:

- Fullterm controls (FTC): $\geqslant 37$ weeks gestational age (GA) with no signs or history of respiratory illness prior to testing.

- Preterm controls (PTC): <37 weeks GA with minimal requirements for ventilatory support (ie, no invasive ventilation, maximum $48 \mathrm{~h}$ support with nasal continuous positive airway pressure, no supplemental inspiratory oxygen $\left(\mathrm{O}_{2}\right)$ after $48 \mathrm{~h}$ postnatal age and no signs or history of respiratory illness prior to testing).

- Respiratory distress syndrome (RDS) <37 weeks GA with a history of resolved respiratory distress syndrome and no requirement for supplemental fractional inspired oxygen $\left(\mathrm{FiO}_{2}\right)$ at 36 weeks postmenstrual age (PMA).

- Chronic lung disease (CLD): requirement for supplemental $\mathrm{FiO}_{2}$ or assisted ventilation at 36 weeks PMA. ${ }^{19}{ }^{20}$

Clinical and demographic data were recorded from hospital notes and parental questionnaires. Weight and length were assessed using standardised methods ${ }^{21}$; results were converted into $z$ scores based on postnatal age adjusted for prematurity. ${ }^{22}$ Body mass index (BMI weight $\times$ length ${ }^{-2}$ ) was calculated as an index of disproportionate growth.

\section{Lung function tests}

Measurements were performed on clinically stable unsedated infants in the supine position during quiet sleep at least $30 \mathrm{~min}$ post-feed. Preterm infants were studied at least once prior to initial hospital discharge, generally between 34 and 38 weeks PMA. When feasible, these infants returned for follow-up studies at approximately 44 weeks PMA in order to match test age more closely with term controls who were only studied once, usually within 4-8 weeks of birth (ie, 44-48 weeks PMA).

Tidal volume $(\mathrm{Vt})$, respiratory rate $(\mathrm{RR}), \mathrm{FRC}$ and indices of ventilation inhomogeneity (Lung Clearance Index (LCI) and first and second moment ratios $\left(\mathrm{M}_{1} / \mathrm{M}_{0}, \mathrm{M}_{2} / \mathrm{M}_{0}\right)$, which are different methods of expressing ventilation efficiency), ${ }^{12}$ were measured using the $\mathrm{MBW}$ technique with $4 \% \mathrm{SF}_{6}$ as a tracer gas using a commercially available prototype ultrasonic flowmeter (Ecomedics AG, Duernten, Switzerland). ${ }^{17}$ Attempts were made to collect three acceptable MBW manoeuvres in each infant within each test occasion (see online supplement).

\section{Statistical models}

Standard software packages were used for data inspection, distribution and descriptive statistics (SPSS for Windows, V.15.0, SPSS). In infants in whom more than one test had been performed, presentation of results in tabular form was limited to data from the last test occasion (ie, one result per subject). All technically valid data from all test occasions were used in multilevel modelling to take account of the correlation between repeat measurements from the same child. Univariable regression analysis established the association between each outcome measure and likely explanatory variables. Where potentially significant associations $(p<0.05)$ existed, these were further explored using multivariable, multilevel linear regression modelling (MLwiN, V.2.12; Institute of Education, UK) using a two level model (centre; subject) and stepwise approach to multivariable model development that aimed to understand the mechanistic basis of differences observed (see online supplement).

\section{RESULTS}

\section{Population characteristics}

Technically acceptable data were obtained from 219 infants on 306 test occasions. Forty-eight infants were tested on two 
Table 2 Test occasion details and main results

\begin{tabular}{|c|c|c|c|c|}
\hline & FTC & PTC & RDS & CLD \\
\hline No of infants & 64 & 59 & 54 & 42 \\
\hline No of tests* & 64 & 94 & 86 & 62 \\
\hline 1 test occasion: $\mathrm{n}$ & 64 & 34 & 30 & 25 \\
\hline 2 test occasions: $n$ & - & 17 & 17 & 14 \\
\hline 3 test occasions: $n$ & - & 6 & 6 & 3 \\
\hline 4 test occasions: $n$ & - & 2 & 1 & - \\
\hline \multicolumn{5}{|c|}{ Details from last test occasion in each infant } \\
\hline PMA (weeks) & $44.2(1.4)$ & $40.2(4.1)$ & $39.7(4.3)$ & $41.3(3.8)$ \\
\hline Weight (kg) & $4.37(0.54)$ & $3.10(1.00)$ & $2.91(0.90)$ & $3.16(0.91)$ \\
\hline Weight z score ${ }^{22}$ & $0.09(0.78)$ & $-0.92(1.08)$ & $-1.11(1.06)$ & $-1.26(1.31)$ \\
\hline Length $(\mathrm{cm})$ & $54.6(2.8)$ & $48.7(4.3)$ & $47.8(4.6)$ & $47.5(3.9)$ \\
\hline Length $z$ score ${ }^{22}$ & $0.29(1.12)$ & $-1.06(1.32)$ & $-1.38(1.39)$ & $-2.2(1.35)$ \\
\hline BMI & $14.6(1.3)$ & $12.7(2.3)$ & $12.4(1.8)$ & $13.7(2.0)$ \\
\hline BMI z score & $-0.55(1.10)$ & $-0.54(0.98)$ & $-0.34(1.18)$ & $0.16(1.27)$ \\
\hline $\mathrm{FRC}(\mathrm{ml})$ & $79.6(14.5)$ & $64.3(15.6)$ & $59.2(16.6)$ & $53.5(15.3)$ \\
\hline $\mathrm{FRC}(\mathrm{ml} / \mathrm{kg})$ & $18.4(3.6)$ & $22.1(6.0)$ & $21.2(5.4)$ & $17.5(4.8)$ \\
\hline $\mathrm{LCl}$ & $7.17(0.54)$ & $7.14(0.88)$ & $6.89(0.74)$ & $7.56(1.12)$ \\
\hline $\mathrm{M}_{1} / \mathrm{M}_{0}$ & $2.12(0.21)$ & $2.08(0.26)$ & $1.99(0.20)$ & $2.22(0.32)$ \\
\hline $\mathrm{M}_{2} / \mathrm{M}_{0}$ & $8.14(2.47)$ & $7.70(2.18)$ & $6.97(1.48)$ & $8.96(2.82)$ \\
\hline Vt (ml) & $29.7(5.9)$ & $21.8(7.0)$ & $19.1(7.0)$ & $18.7(6.1)$ \\
\hline $\mathrm{Vt}(\mathrm{ml} / \mathrm{kg})$ & $6.8(1.3)$ & $7.2(1.2)$ & $6.6(1.5)$ & $6.0(1.0)$ \\
\hline $\mathrm{RR}(/ \mathrm{min})$ & 47 (12) & $53(13)$ & $53(14)$ & $59(16)$ \\
\hline $\mathrm{MV}(\mathrm{ml} / \mathrm{kg})$ & $311(57)$ & $362(87)$ & $336(74)$ & $345(83)$ \\
\hline
\end{tabular}

Results are expressed as mean (SD).

*Total number of tests used for multivariable and multilevel analysis.

BMI, body mass index; CLD, chronic lung disease; FRC, functional residual capacity; FTC, full term controls; LCI, lung clearance index; $\mathrm{M}_{1} / \mathrm{M}_{0}$ and $\mathrm{M}_{2} / \mathrm{M}_{0}$, 1st and 2nd moment ratios; MV, minute volume; PMA, postmenstrual age; PTC, preterm controls; $\mathrm{RDS}$, respiratory distress syndrome; $\mathrm{RR}$, respiratory rate; $\mathrm{Vt}$, tidal volume.

occasions, 15 on three occasions and three infants on four occasions. Overall failure rate was 10\% (see online supplement). As expected, there were significant differences in background characteristics and ventilatory support according to diagnostic category (table 1, and see fig OLS 1 available online).

\section{Test occasion details}

PMA at the time of testing ranged from 39 to 47 weeks among the fullterm infants, which overlapped with that for all those born preterm (see fig OLS 1D online). Despite this overlap, the preterm groups (controls, CLD and RDS) were less mature, shorter and lighter at the time of the test compared with term controls (table 2, and figs OLS 2 and OLS 3 online). There was evidence of growth restriction among all preterm groups in whom length and weight $z$ scores were significantly lower than in term infants. This discrepancy was particularly marked in those with CLD who were very short for their weight (fig OLS 3 online). Reflecting this growth pattern, CLD infants also had a higher body mass index at the time of the test compared with the PTC or RDS group.
Figure 1 Functional residual capacity (FRC) according to diagnostic category: fullterm control (FTC; $n=64)$; preterm control (PTC; $n=59$ ); preterm respiratory distress syndrome (RDS; $n=54$ ); and preterm chronic lung disease (CLD; $\mathrm{n}=42$ ). In infants in whom more than one test had been performed, presentation of results in the figure is limited to data from the last test occasion (ie, one result per subject). While there were significant differences between the fullterm and preterm groups due to differences in body size at the time of the test (A) (see table 2 also), simply expressing results as $\mathrm{FRC} / \mathrm{kg}$ as shown in $(B)$, would have led to misleading conclusions because of the disproportionate growth patterns among the preterm groups (see table 2 and text for details).
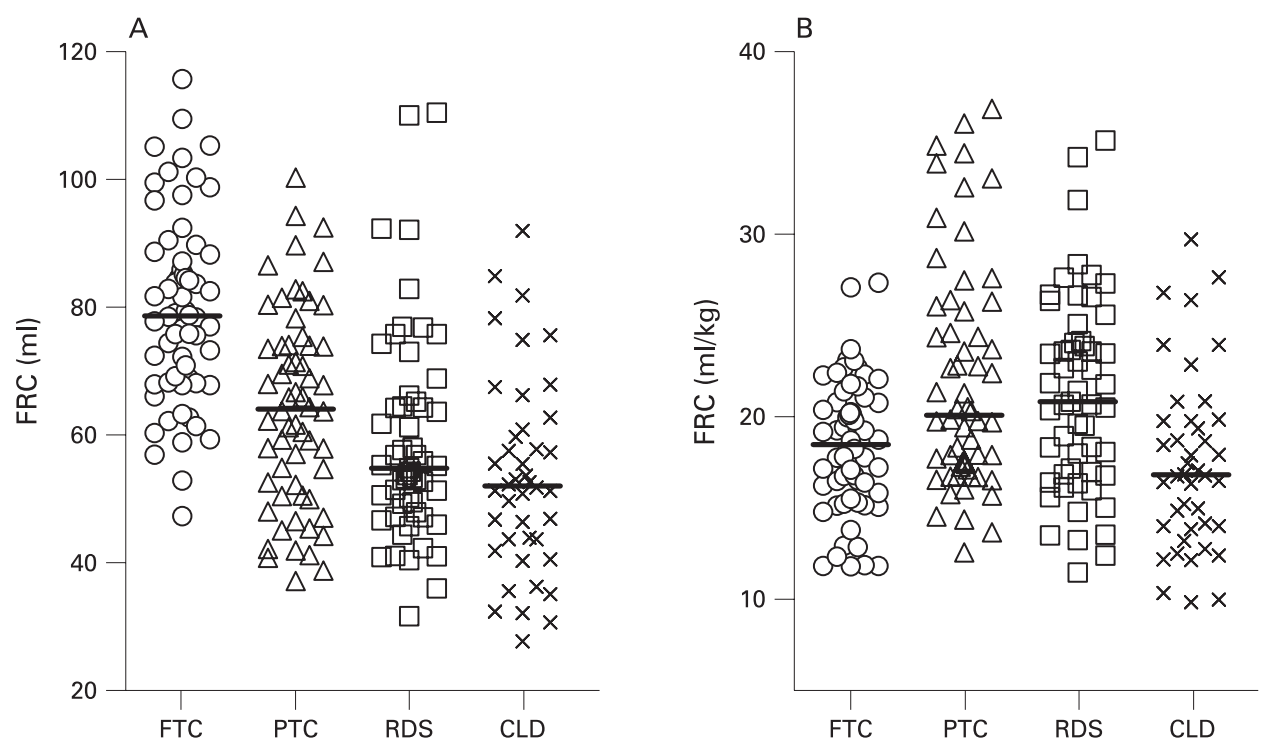


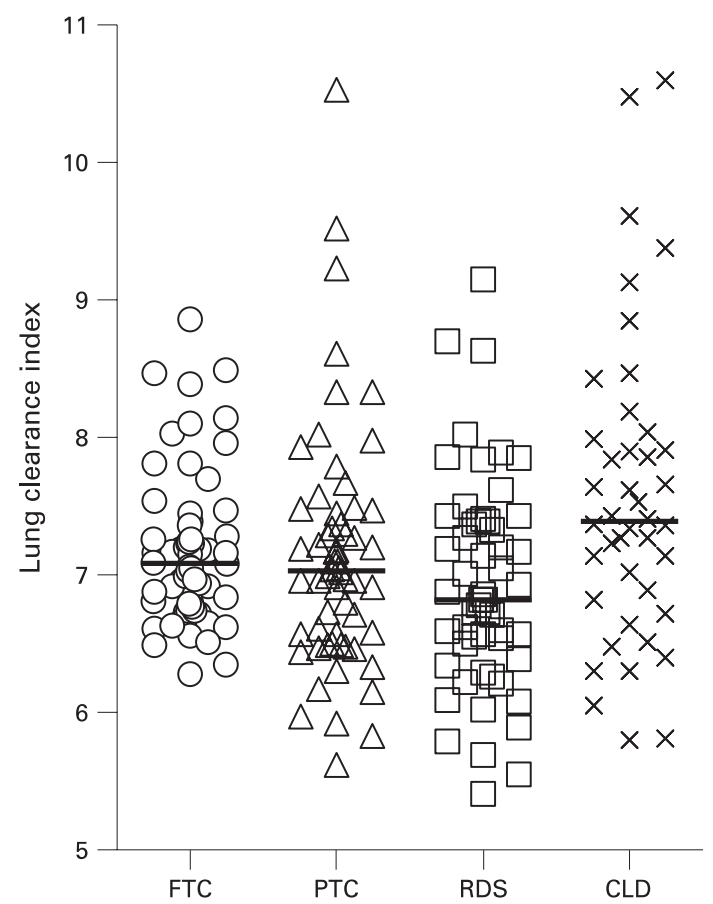

Figure 2 Lung clearance index ( $\mathrm{LCl}$ ) according to diagnostic category: fullterm control (FTC; $n=64)$; preterm control (PTC; $n=59)$; preterm respiratory distress syndrome (RDS; $n=54)$; preterm chronic lung disease (CLD; $n=42$ ). In infants in whom more than one test had been performed, presentation of results in the figure is limited to data from the last test occasion (ie, one result per subject).

\section{Lung function outcomes}

Within test variability, as measured by average SD for differences between replicate measurements on the same test occasion was 0.56 (LCI), $0.15\left(\mathrm{M}_{1} / \mathrm{M}_{0}\right)$ and $1.26\left(\mathrm{M}_{2} / \mathrm{M}_{0}\right)$, respectively. No significant differences in variability between fullterm and preterm infants were observed for indices of ventilation inhomogeneity. In contrast, the average SD for FRC in preterm infants $(1.88 \mathrm{ml} / \mathrm{kg})$ was significantly higher $(\mathrm{p}=0.004)$ than in fullterm infants $(1.37 \mathrm{ml} / \mathrm{kg})$.

\section{Summary of univariable analysis}

As expected, on univariable analysis, body size and age at test were significantly associated with FRC, Vt and RR, as were a wide range of potential determinants, including GA, birth weight and birth weight $\mathrm{z}$ score, severity of neonatal respiratory disease (both duration of $\mathrm{O}_{2}$ requirements and total ventilation days) and maternal smoking during pregnancy. In contrast, indices of ventilation inhomogeneity (LCI, $M_{1} / M_{0}$ and $M_{2} / M_{0}$ ) were not associated with either current age or body size or with any other variable except disease severity, for which there was a very small but significant contribution. Sex and ethnic group had no effect on any outcome variable except RR and MV, which was lower among Caucasian infants (see table OLS 1 online).

\section{Functional residual capacity}

Figure 1 shows both absolute FRC and FRC/kg body weight according to diagnostic category. (Scatterplots of FRC in relation to age, weight, length and BMI are shown in fig OLS 4 online.) Multivariable analysis demonstrated that after adjustment for centre, length and BMI, PMA and weight at the time of the test no longer had any effect on FRC. After correcting for body size, being preterm resulted in a significant decrement of $0.5 \mathrm{ml}$ /weeks GA while intrauterine growth restriction was associated with an average reduction of $1.9 \mathrm{ml}$ per unit reduction in birth weight $\mathrm{z}$ score. FRC was further reduced by $0.04 \mathrm{ml} /$ day of supplemental $\mathrm{O}_{2}$ (see table OLS 2 online). Having these factors accounted for, diagnostic category had no additional effect. However, there were additional equipment differences. Compared with FRC data from $\mathrm{HUH}$ collected using equipment 2, those from UCLH and KEMH (equipment 1) were significantly lower $(p<0.0001)$ by an average of $8.6 \mathrm{ml}$. Despite these equipment variations, the strength of associations between FRC and length, BMI, GA, birth weight $\mathrm{z}$ score and days of supplemental $\mathrm{O}_{2}$ remained unchanged (see online supplement).

\section{Ventilation inhomogeneity}

Figure 2 shows LCI according to disease category, with similar plots for moment ratios shown in fig OLS 6 (available online). As expected, indices of ventilation inhomogeneity were not associated with age or body size at the time of the test, derived values already being "internally corrected" by adjusting for FRC. On multivariable analysis, the only factor significantly associated with LCI was disease severity, being 0.003 higher/day supplemental $\mathrm{O}_{2}$ (table OLS 3, fig OLS 5 available online). The association with $\mathrm{O}_{2}$ remained significant after adjusting for FRC. LCI data from KEMH and UCLH (equipment 1) was 0.34 lower than that from HUH $(p<0.0001)$.

\section{Tidal breathing indices}

RR fell with increasing age (table OLS 6 online). After adjusting for BMI and age at test, ethnic group no longer had any significant influence on RR. Slightly lower rates were found in boys whereas higher rates were associated with intrauterine growth restriction and disease severity but not with prematurity. No equipment differences were observed for RR.

\section{Tidal volume}

After adjusting for current age and body size, Vt was significantly and positively associated with gestational age and intrauterine growth (table OLS 7 online) but not with either disease severity or diagnostic category. Equipment effects were observed, with Vt from HUH being on average $2.6 \mathrm{ml}$ higher $(p<0.0001)$ than that from KEMH and UCLH.

\section{Minute volume}

After adjusting for current weight, equipment set was the only factor significantly associated with minute volume on multivariable analysis, this being on average $96 \mathrm{ml}$ higher for equipment set 2 (HUH) (table OLS 8 online).

\section{DISCUSSION}

This multicentre investigation represents the largest of its kind and the first to use sophisticated statistical modelling to explore the mechanistic basis for changes in infant lung function caused by immaturity and/or lung disease after accounting for known determinants such as age and body size. By enrolling a large cohort of newborns, including term and preterm controls as well as those recovering from respiratory disease, we were able to adopt a more clinically plausible approach using continuous measures of immaturity and disease severity, rather than simply categorising infants according to somewhat arbitrary definitions. After adjusting for equipment, age and body size at the time of the test, reductions in gestation and birth weight $z$ score 
were both associated with a lower FRC, together with a small but significant contribution of disease severity (supplemental $\mathrm{O}_{2}$ days). These findings support contemporary concepts of disturbed lung growth after preterm birth, and suggest that a significant proportion of the abnormal lung function associated with chronic lung disease can be accounted for by the degree of prematurity and intrauterine growth restriction. In contrast, pre and postnatal growth patterns had little impact on LCI, which was only affected by duration of $\mathrm{O}_{2}$.

\section{Strengths and limitations}

Important strengths of this study include the large study group, multicentre recruitment and inclusion of prospective preterm and fullterm controls. Extensive quality control in accordance with international standards was applied to data collection and analysis, with sophisticated and robust statistical methodology being used to explore the complex interactions within the data. Although we summarised our data according to diagnostic categories to facilitate comparison with the previous literature, we addressed the potential problems arising from such categorisation by using continuous variables of disease severity and immaturity during multivariable analysis.

The inter-centre differences observed in this study were unexpected as the same investigators were involved at all three sites, and we had used the same methods and type of equipment. Further investigations using multilevel modelling indicated that these centre differences were primarily associated with which set of equipment was used. Given that FRC was approximately three times $\mathrm{Vt}$ (table 2), there appears to be internal consistency in that an overestimation of $2.6 \mathrm{ml}$ in $\mathrm{Vt}$ would multiply to one of around $8 \mathrm{ml}$ for FRC. We can only surmise the presence of subtle differences in hardware or software of this prototype USFM device that, despite extensive investigation, we were unable to detect (see online supplement for details). Fortunately, sample size was sufficiently large to allow us to model for these differences, which did not affect the overall conclusions of the study. However, such differences could have confounded a smaller study or one relying on normative data collected elsewhere; this highlights the need to recruit prospective controls in such studies.

\section{Determinants of neonatal lung function}

The rapid somatic and lung growth that occur in the first months of life must be properly accounted for if the impact of either prematurity or lung disease on lung function is to be determined reliably. Height (or length) is known to be the major determinant of FRC, ${ }^{23}$ as confirmed in this study. Lung function is commonly corrected for differences in body size during the neonatal period simply by dividing by body weight (see fig 1B). In the presence of low weight $\mathrm{z}$ scores, this practice will overestimate reported values. In contrast, in the presence of high "weight-for-length" or age, values will be underestimated. The combination of both situations, as seen among the CLD infants (table 2), can totally confound interpretation of the results. In this study, adjustment for age and body size was achieved by repeating tests in the preterm infants to overlap with the age at which fullterm infants were studied and by using appropriate statistical models. Inappropriate adjustment for growth could be responsible for much of the conflicting evidence regarding neonatal lung function..$^{94}$

Although birth weight is a known determinant of lung function throughout life, ${ }^{25-29}$ this is a complex factor which encompasses both maturation and adequacy of intrauterine growth. In our study, the combination of gestation and birth weight $\mathrm{z}$ score explained more variability than birth weight alone, and provided some insight into mechanisms underlying the variability of neonatal lung function. Our findings show that maturity at birth and intrauterine growth are independently predictive of tidal volume and FRC soon after birth, and that intrauterine growth also influences RR.

\section{Comparison with published literature}

The multivariable statistical approach used in this study differs substantially from previous reports that have relied on tests or ANOVA. ${ }^{8031}$ In addition, in contrast with previous publications, by entering each category into the models as separate factors, the patterns of association could emerge without prior assumptions being made as to the nature of the differences expected. In this study, Vt, RR and FRC were primarily influenced by markers of maturity, intrauterine growth, disease severity and postnatal anthropometry. FRC is frequently used to monitor lung disease during infancy and early childhood. Reports of a lower FRC at term/near term for infants with CLD compared with healthy controls in the pre-surfactant era $^{32}$ have been reconfirmed by several studies in the post-surfactant era. ${ }^{8}{ }^{30}$ 33 More recent studies have shown that preterm birth per se and lung disease requiring treatment may have independent effects on lung volume, ${ }^{31}{ }^{34}$ although restricted sample sizes have often limited power to fully elucidate factors influencing neonatal lung function. Like Hjalmarson and Sandberg, ${ }^{31}$ we observed lower FRC in preterm than term controls at a comparative postmenstrual age, although differences are not as obvious when FRC is plotted against length (fig OLS 4 online). A more recent study presented findings on infants with CLD and RDS, as well as controls ${ }^{8}$ but did not report length or any differences in the proportionality of growth between groups with which to compare our data. Whereas we acknowledge the ideal of matching for postmenstrual age, this was impractical. We thus prioritised modelling for other highly variable factors likely to have a greater effect on lung function than PMA per se.

The recent interest in assessing ventilation inhomogeneity in preterm infants ${ }^{811303135}$ is not surprising, given that neonatal respiratory disease is dominated by abnormalities of the lung periphery and interrupted acinar development. ${ }^{46}$ Increases in either LCI or moment ratios signify reduced ventilation efficiency. Our observation that duration of $\mathrm{O}_{2}$ is positively associated with increased ventilation inhomogeneity is consistent with previous studies ${ }^{8}$ although the effect size was small. Importantly, we did not find evidence to support a preliminary report that LCI decreased with advancing postnatal age during the neonatal period. ${ }^{37}$ LCI is corrected for FRC, and hence the lack of an association between LCI and body size is not surprising. The indices we studied were also influenced by breathing patterns, ${ }^{38}$ particularly dead space/tidal volume and $\mathrm{Vt} / \mathrm{FRC}$ ratios. In contrast with its proven utility when detecting early lung disease in sedated infants with cystic fibrosis, ${ }^{39}$ indices of ventilation inhomogeneity may be less useful when assessing the effect of prematurity or lung disease in small unsedated neonates.

\section{Conclusions}

Sophisticated analysis of this large study has highlighted the complexity of factors contributing to lung function outcomes after preterm birth. Lung volume and tidal breathing parameters are influenced by intrauterine growth, maturity at birth, anthropometry and disease severity, whereas disease severity 
alone has a small but significant influence on ventilation inhomogeneity. These findings support contemporary concepts of disturbed lung growth after preterm birth, and suggest that a significant proportion of the abnormal lung function associated with chronic lung disease can be accounted for by the degree of prematurity and intrauterine growth. Disproportionate growth patterns following preterm delivery raise concerns about potential misinterpretation of studies using simplistic normalisation of variables such as $\mathrm{FRC} / \mathrm{kg}$ to compare disparate subject groups. The contribution of equipment differences to most of the outcome measures further highlights the importance of recruiting a prospective control group for such investigations. Only by using multivariable analysis were we able to account for the multiple complex and interacting determinants of lung function and distinguish the effects of prematurity and lung disease from those of growth and development.

Acknowledgements: The authors thank the babies and their parents who participated in this study, and the staff of the neonatal units at University College London Hospital, Homerton University Hospital and King Edward Memorial Hospital. We also thank Ms Anne Cantarella, Ms Kerry Williams, Dr David Baldwin and Dr Sanjay Sinhal, who provided valuable assistance in subject recruitment and obtaining the measurements.

Funding: Supported by the Innovative Medizinische Forschung, University of Münster and the Gesellschaft für Pädiatrische Pneumologie, Germany (GH), a Neil Hamilton Fairley NHMRC Postdoctoral Fellowship and NHMRC Career Development Award (JP) and Portex Ltd (JS). Research at the Institute of Child Health and Great Ormond Street Hospital for Children NHS Trust benefits from R\&D funding received from the NHS Executive. Research at King Edward Memorial Hospital was supported by grants from the Women \& Infants Research Foundation and the Raine Medical Research Foundation.

Competing interests: The authors (JS, SL, JP) received some research discount on equipment supplied by EcoMedics in association with undertaking studies contributing to the development of the EcoMedics infant multiple breath washout equipment and software.

Ethics approval: The study was approved by the local research ethics committees.

\section{REFERENCES}

1. Jobe $\mathbf{A H}$, Ikegami M. Prevention of bronchopulmonary dysplasia. Curr Opin Pediatr 2001;13:124-9.

2. Coalson JJ. Pathology of new bronchopulmonary dysplasia. Semin Neonatol 2003;8:73-81.

3. Allen J, Zwerdling R, Ehrenkranz R, et al. Statement on the care of the child with chronic lung disease of infancy and childhood. Am J Respir Crit Care Med 2003; 168:356-96.

4. Jobe AH, Bancalari E. Bronchopulmonary dysplasia. Am J Respir Crit Care Med 2001;163:1723-9.

5. Ehrenkranz RA, Walsh MC, Vohr BR, et al. Validation of the National Institutes of Health consensus definition of bronchopulmonary dysplasia. Pediatrics 2005;116:1353-60.

6. Walsh MC, Yao Q, Gettner P, et al. Impact of a physiologic definition on bronchopulmonary dysplasia rates. Pediatrics 2004;114:1305-11.

7. Walsh MC, Szefler S, Davis J, et al. Summary proceedings from the bronchopulmonary dysplasia group. Pediatrics 2006;117:S52-6.

8. Hjalmarson 0, Sandberg KL. Lung function at term reflects severity of bronchopulmonary dysplasia. J Pediatr 2005;146:86-90.

9. Hulskamp G, Pillow JJ, Dinger J, et al. Lung function tests in neonates and infants with chronic lung disease of infancy: functional residual capacity. Pediatr Pulmonol 2006;41:1-22.

10. Hulskamp G, Hoo AF, Ljungberg $H$, et al. Progressive decline in plethysmographic lung volumes in infants: physiology or technology? Am J Respir Crit Care Med 2003;168:1003-9.
11. Pillow JJ, Frerichs I, Stocks J. Lung function tests in neonates and infants with chronic lung disease: global and regional ventilation inhomogeneity. Pediatr Pulmonol 2006; 41:105-21.

12. Latzin $\mathbf{P}$, Thamrin $\mathrm{C}$, Kraemer R. Ventilation inhomogeneities assessed by the multibreath washout (MBW) technique. Thorax 2008;63:98-9.

13. Buess C, Pietsch P, Guggenbuhl W, et al. A pulsed diagonal-beam ultrasonic airflow meter. J App/ Physiol 1986;61:1195-9.

14. Schibler A, Henning R. Measurement of functional residual capacity in rabbits and children using an ultrasonic flow meter. Pediatr Res 2001;49:581-8.

15. Schibler A, Hall GL, Businger F, et al. Measurement of lung volume and ventilation distribution with an ultrasonic flow meter in healthy infants. Eur Respir $J$ 2002;20:912-18.

16. Wauer J, Leier TU, Henschen $\mathrm{M}$, et al. In vitro validation of an ultrasonic flowmeter in order to measure the functional residual capacity in newborns. Physiol Meas 2003;24:355-65.

17. Pillow JJ, Ljungberg $\mathrm{H}$, Hulskamp G, et al. Functional residual capacity measurements in healthy infants: ultrasonic flow meter versus a mass spectrometer. Eur Respir J 2004;23:768.

18. Lum S, Hoo AF, Dezateux C, et al. The association between birthweight, sex, and airway function in infants of nonsmoking mothers. Am J Respir Crit Care Med 2001;164:2078-84.

19. Shennan AT, Dunn MS, Ohlsson A, et al. Abnormal pulmonary outcomes in premature infants: prediction from oxygen requirement in the neonatal period. Pediatrics 1988;82:527-32.

20. Charafeddine L, D'Angio CT, Phelps DL. Atypical chronic lung disease patterns in neonates. Pediatrics 1999;103:759-65.

21. Gaultier C, Fletcher M, Beardsmore $C$, et al. Respiratory function measurements in infants: Measurement conditions. Am J Respir Crit Care Med 1995;151:2058-64.

22. Freeman JV, Cole TJ, Chinn S, et al. Cross sectional stature and weight reference curves for the UK, 1990. Arch Dis Child 1995;73:17-24.

23. Stocks J, Quanjer PH. Reference values for residual volume, functional residual capacity and total lung capacity ATS Workshop on Lung Volume Measurements. Official statement of the European Respiratory Society. Eur Respir J 1995:492-506.

24. Hulskamp G, Pillow JJ, Stocks J. Lung function testing in acute neonatal respiratory disorders and chronic lung disease of infancy: a review series. Pediatr Pulmonol 2005:40:467-70.

25. Sharma P, McKay K, Rosenkrantz TS, et al. Comparisons of mortality and predischarge respiratory outcomes in small-for-gestational-age and appropriate-forgestational-age premature infants. BMC Pediatr 2004:4:9.

26. Torrance HL, Voorbij HA, Wijnberger LD, et al. Lung maturation in small for gestational age fetuses from pregnancies complicated by placenatal insufficiency or maternal hypertension. Early Hum Dev 2008:84:465-9.

27. Hoo AF, Stocks J, Lum S, et al. Development of lung function in early life: influence of birth weight in infants of nonsmokers. Am J Respir Crit Care Med 2004;170:527-33.

28. Chan KN, Noble-Jamieson CM, Elliman A, et al. Lung function in children of low birth weight. Arch Dis Child 1989;64:1284-93.

29. Canoy D, Pekkanen J, Elliott $P$, et al. Early growth and adult respiratory function in men and women followed from the fetal period to adulthood. Thorax 2007;62:396-402.

30. Shao H, Sandberg K, Hjalmarson O. Impaired gas mixing and low lung volume in preterm infants with mild chronic lung disease. Pediatr Res 1998;43:536-41.

31. Hjalmarson 0, Sandberg K. Abnormal lung function in healthy preterm infants. Am J Respir Crit Care Med 2002;165:83-7.

32. Gerhardt T, Hehre D, Feller $R$, et al. Serial determination of pulmonary function in infants with chronic lung disease. J Pediatr 1987;110:448-56.

33. de Winter JP, Merth IT, Brand R, et al. Functional residual capacity and static compliance during the first year in preterm infants treated with surfactant. Am J Perinatol 2000;17:377-84.

34. Kavvadia V, Greenough A, Itakura $Y$, et al. Neonatal lung function in very immature infants with and without RDS. J Perinat Med 1999;27:382-7.

35. Shao H, Sandberg K, Sjoqvist BA, et al. Moment analysis of multibreath nitrogen washout in healthy preterm infants. Pediatr Pulmonol 1998;25:52-8.

36. Coalson JJ, Winter V, DeLemos RA. Decreased alveolarization in baboon survivors with bronchopulmonary dysplasia. Am J Respir Crit Care Med 1995;152:640-6.

37. Pillow JJ, Hulskamp G, Stocks J. Lung clearance index changes with maturation in preterm neonates. Eur Respir J 2005;26(Suppl 49):6s.

38. Habib RH, Lutchen KR. Moment analysis of a multibreath nitrogen washout based on an alveolar gas dilution number. Am Rev Respir Dis 1991;144:513-19.

39. Lum S, Gustafsson $\mathrm{P}$, Ljungberg $\mathrm{H}$, et al. Early detection of cystic fibrosis lung disease: multiple-breath washout versus raised volume tests. Thorax 2007:62:341-7. 